\title{
Determination of the Volatile Constituents in Banana Flowers and Bracts by Headspace Solid-Phase Microextraction and Gas Chromatography - Mass Spectrometry
}

\author{
Yuanmin Wang $^{1}$, Xiangpei Wang ${ }^{1}$, Feng $\mathrm{Xu}^{1}$ And Hongmei $\mathrm{Wu}^{1, \mathrm{a}}$ \\ ${ }^{1}$ Pharmacy college, Guiyang College of Traditional Chinese Medicine, Guiyang, Guizhou, PR China \\ Keywords: Headspace solid-phase microextraction and gas chromatography - mass spectrometry; Musa balbisiana \\ Colla, Men.; Banana flowers and banana bracts; Volatile constituents
}

\begin{abstract}
The volatile constituents in banana flowers and banana bracts were analyzed by gas chromatography-mass spectrometry, coupled with headspace solid-phase microextraction. A quantitative analysis in percent was performed by peak area normalization measurements. 31 compounds were identified in banana flowers accounting for $97.78 \%$ of the total volatiles and 16 compounds were identified in banana bracts accounting for $93.54 \%$ of the total volatiles. Nonanal was the highest ingredient in banana flowers and banana bracts $(72.67 \%$ and $48.77 \%$, respectively). The two herbs have 11 mutual compounds, accounting for $91.79 \%$ and $90.62 \%$ of total volatile components in banana flowers and bracts, respectively. Some of volatile compounds in two herbs with high concentration were hexanal, 2-pentyl-furan, octanal, isoamyl butyrate, nonanal. The study could provide a method to indentify and compare the difference of the volatile components in the flowers and bracts.
\end{abstract}

\section{INTRODUCTION}

Musa balbisiana Colla, Men. belongs to Musaceae family, it widely distribute in Guangdong, Guangxi, Taiwan, Fujian, Hainan, Yunnan province of China. The bananas are ripe, the banana flowers and bracts are usually discarded as waste, and it is a scientific problem to utilize the banana by-products [1]. According to reports, in many Asian countries (such as Indonesia, the Philippines, Laos, and Myanmar) the banana flowers are used as vegetables [2] and medicine to increase the milk of lactating women, treat dysmenorrhea and diabetes [3, 4]. Modern researches show that the banana flowers contain rich minerals, protein, amino acids, fiber [5]. Moreover, the saponins, flavonoids are the main chemical in banana flower with antioxidant activity [6, 7]. In the banana bracts, the total phenols can inhibit lipid peroxidation and radical scavenging activity [8]. Banana flowers and bracts a Correspondence to: whm0425@126.com 
have fragrance, but the banana flowers have a richer flavor than bracts. The differences of volatile components in two samples were unclear. In this study, the headspace solid-phase micro-extraction and gas chromatography-mass spectrometry technique were used to analyze banana flowers and bracts volatile constituents (Musa balbisiana Colla, Men.) combined with retention index and the differences of the two herbs were compared. The purpose of this study is to explain that banana flowers have a richer flavor than bracts. This work could provide a scientific basis for the further development and utilization of banana flowers and bracts.

\section{Experimental section}

Banana (Musa balbisiana Colla, Men.) flowers and banana (Musa balbisiana Colla, Men.) bracts were collected from Tibet Motuo County and identified by Professor Xiang-pei Wang of Guiyang College Traditional of Chinese Medical. The two samples were deposited in the Department of Pharmacognosy, Guiyang College of Traditional Chinese Medicine, PR. China. The two samples were separated from spikes terminal of banana and were dried in room temperature (temperatures between $20-30^{\circ} \mathrm{C}$ ).

The chromatographic analysis was performed on a Hewlett-Packard 6089 gas chromatography (Agilent Technologies, Palo, Alto, Calif., U.S.A.) equipped with an electronic pneumatically controlled spilt injector and a flame-ionization detector. The solid-phase microextraction manual fiber holder and a carboxene-polydimethrlsioxane microextraction fiber were purchased from Supelco (Bellefonte, Pennylvania, USA).

\section{Headspace solid-phase microextraction procedure}

In this work, $8.0 \mathrm{~g}$ accurately weighed small pieces of two samples were placed into $50 \mathrm{ml}$ solid-phase microextraction instrument sampling bottles. A $2 \quad \mathrm{~cm}-50 / 30$ um divinylbenzene-carboxen-polydimethylsiloxane (DVB/CAR/PDMS) fiber was used to expose the headspace above the sample at $85^{\circ} \mathrm{C}$ for $30 \mathrm{~min}$. then the headspace solid-phase microextraction fiber head was heated in the injecting port at $250^{\circ} \mathrm{C}$ for $3 \mathrm{~min}$ and directly desorbed and analyzed.

\section{Gas chromatography-mass spectrometry condition}

The analyses were performed using a Hewlett-Packard (HP) 6890 gas chromatography with a 5973C mass selective (Agilent Technologies, Palo, Alto, Calif., U.S.A.), The mass spectrometer was fitted with an electron ionization source operated at $70 \mathrm{eV}$, the source temperature was set at $230{ }^{\circ} \mathrm{C}$, the ion trap operating in scanning mode and the scan range was $\mathrm{m} / \mathrm{z} 20$ to 450 at a scan rate of $1 \mathrm{scan} / \mathrm{s}$. The separation was performed using a $30 \mathrm{~m} \times 0.25 \mathrm{~mm} \times 0.25 \mu \mathrm{m} 5 \%$ phenyl- $95 \%$ dimethylpolysiloxane column. Helium (purity 99.999\%) was used as a carrier with a constant flow velocity of $1 \mathrm{ml} / \mathrm{min}$. The quadrupole mass filter was set at $150{ }^{\circ} \mathrm{C}$. The transfer was operated as follows: held at $40{ }^{\circ} \mathrm{C}$ for $2 \mathrm{~min}$, ramped to $220^{\circ} \mathrm{C}$ at a rate of $4{ }^{\circ} \mathrm{C} / \mathrm{min}$, ramped to $250^{\circ} \mathrm{C}$ at a rate of $4{ }^{\circ} \mathrm{C} / \mathrm{min}$ and held for $2 \mathrm{~min}$.

\section{Data-analysis section}

Comparing the obtained mass spectra of the analytes with the authentic standards of NIST (national institute of standards and technology) 2005 library and Wiley275 library, the volatile compounds were identified. 


\section{Results and discussion}

Headspace solid-phase microextraction method is a solvent-free, rapid method to analyze the volatile components compared with steam distillation method [12]. A 5\% phenyl-95\% dimethylpolysiloxane stable flex fiber has higher reproducibility, higher sensitivity, higher insert, and it can be used to extract varieties of volatiles in banana flowers and bracts. Optimum extraction temperature, equilibrium time and exposure time of headspace solid-phase microextraction were also evaluated. The established condition of gas chromatography-mass spectrometry can achieve the purpose of analyzing and comparing all the volatile constituents of banana flowers and bracts.

\section{The volatile components of the banana flowers and bracts}

Under the established experimental conditions, the volatile components were isolated and identified. The total ion chromatogram of banana flowers and bracts are shown in Fig. 1 and Fig. 2, and the corresponding volatile compounds are listed in Table 1 . The volatile compounds were identified by matching mass spectra with spectra of reference compounds in Nist (national institute of standards and technology) and Wiley mass spectral libraries. The peak area normalization method was used to determine the relative concentrations of the two samples.

It could be found in table 1 that 40 compounds were obtained from the banana flowers, and 31 compounds were identified. The components with high concentrate were aldehydes $(88.50 \%)$, ketones $(0.63 \%)$, alcohols $(1.64 \%)$, esters $(1.37 \%)$, and hydrocarbons $(4.37 \%)$. The main aldehydes were nonanal (72.67\%), heptanal (7.27\%), hexanal (4.80\%) and octanal (1.99\%).

26 compounds were obtained in banana bracts, and 16 compounds were identified (table 1). The components with high concentrate were aldehydes (82.58\%), ketones (3.55\%), esters (3.25\%), and hydrocarbons (1.07\%). The main aldehydes were nonanal (48.77\%), hexanal (20.68\%), heptanal (3.88\%), octanal (5.28\%), decanal (1.85\%), 3-methy-1-butanal (1.15\%), 1-cyclohexen-1-al (0.36\%).

Fig.1The total ion chromatograms of the volatile from banana flowers. Numbered peaks are listed in Table 1.

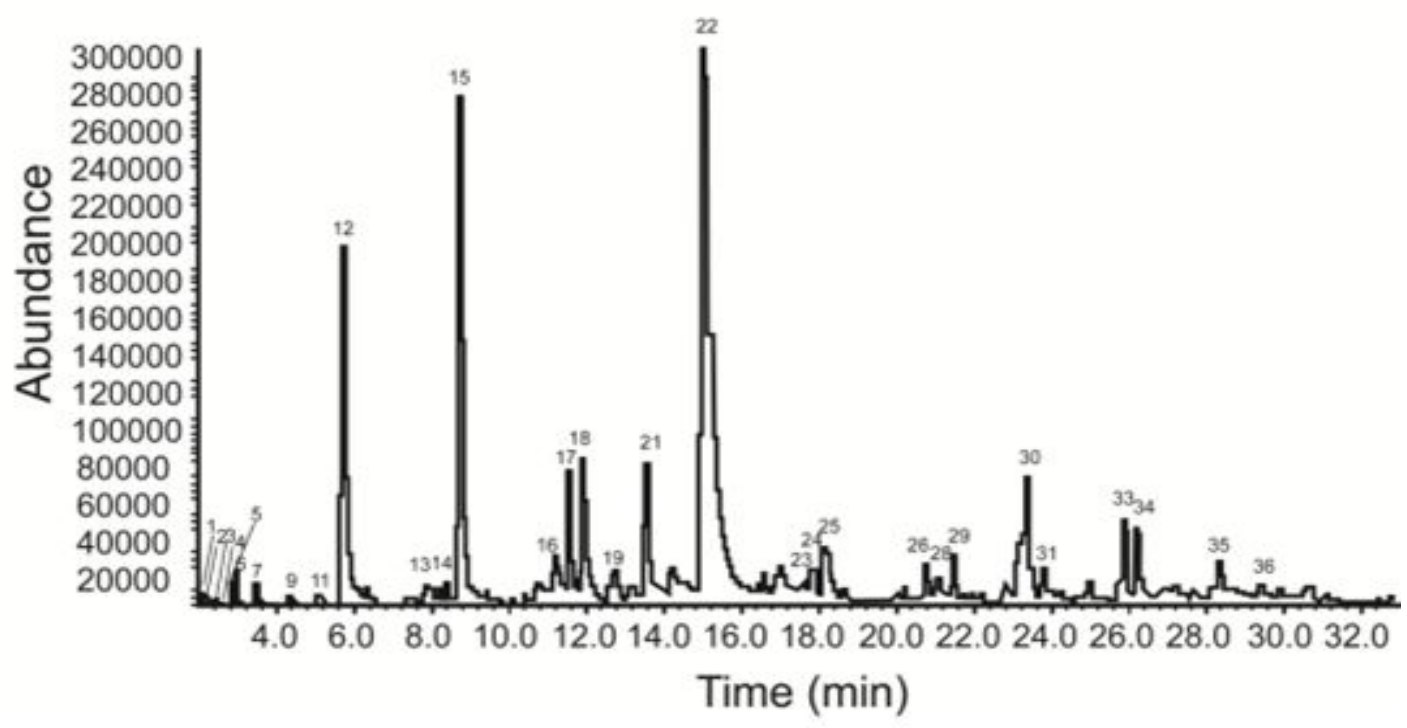


Fig.2The total ion chromatograms of the volatile from banana bracts. Numbered peaks are listed in Table 1.

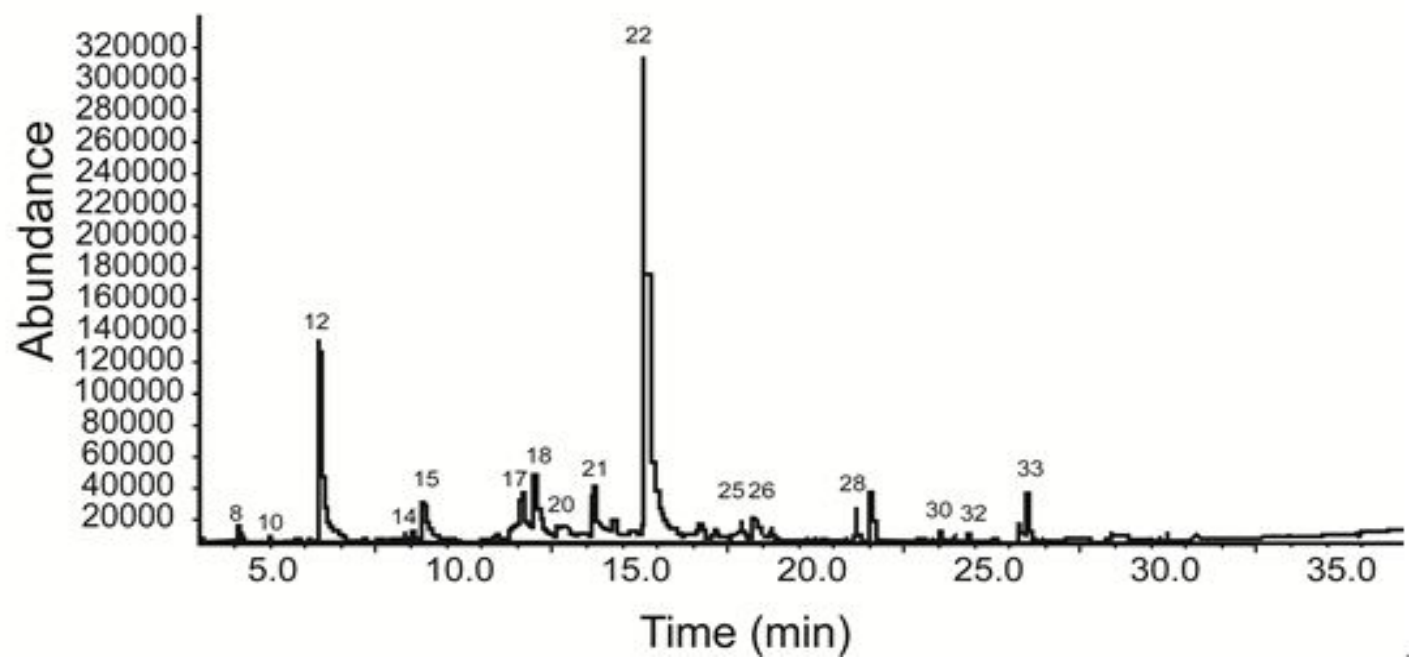

Table 1 Volatile components and the percentage of banana flowers and bracts

\begin{tabular}{|c|c|c|c|c|}
\hline \multirow[t]{2}{*}{ S. No. } & \multirow{2}{*}{$\begin{array}{l}\text { Retention } \\
\text { time(min) }\end{array}$} & \multirow[t]{2}{*}{ Compound name } & \multicolumn{2}{|c|}{ The percentage (\%) } \\
\hline & & & Banana flowers & Banana bracts \\
\hline 1 & 2.10 & ethanal & 0.46 & - \\
\hline 2 & 2.24 & ethanol & 0.01 & - \\
\hline 3 & 2.35 & acetone & 0.15 & - \\
\hline 4 & 2.67 & butanal & 0.06 & - \\
\hline 5 & 3.59 & 3-methyl-1-butanal & 0.13 & - \\
\hline 6 & 3.72 & 2-methyl-1-butanal & 0.22 & - \\
\hline 7 & 4.24 & 2-pentanol & 0.19 & - \\
\hline 8 & 4.25 & 3-methyl-1-butanal & - & 1.15 \\
\hline 9 & 5.11 & 2,5-octadiene & 0.09 & - \\
\hline 10 & 5.12 & 1-cyclohexen-1-al & - & 0.36 \\
\hline 11 & 5.85 & 1-pentanol & 0.25 & - \\
\hline 12 & 6.47 & hexanal & 4.80 & 20.68 \\
\hline 13 & 8.64 & 1-hexanol & 0.50 & - \\
\hline 14 & 8.98 & 1-acetylcyclohexene & 0.12 & 0.52 \\
\hline 15 & 9.47 & heptanal & 7.27 & 3.88 \\
\hline 16 & 11.96 & 1-hepten-3-ol & 0.60 & - \\
\hline 17 & 12.29 & 2-pentyl-furan & 1.03 & 2.50 \\
\hline 18 & 12.64 & octanal & 1.99 & 5.28 \\
\hline 19 & 13.49 & limonene & 0.33 & - \\
\hline 20 & 13.58 & 4-nonyne & - & 0.55 \\
\hline 21 & 14.30 & isoamyl butyrate & 1.37 & 3.25 \\
\hline 22 & 15.81 & nonanal & 72.67 & 48.77 \\
\hline 23 & 18.56 & 4-methyl-6-hepten-3-ol & 0.23 & - \\
\hline 24 & 18.66 & dodecane & 0.21 & - \\
\hline 25 & 18.88 & decanal & 0.90 & 1.85 \\
\hline 26 & 19.37 & $\beta$-cyclocitral & - & 0.61 \\
\hline 27 & 21.48 & tridecane & 0.39 & - \\
\hline 28 & 21.83 & $\begin{array}{l}\text { 5-(2-methylenecyclohexyl)-2-p } \\
\text { entanone }\end{array}$ & 0.28 & 1.62 \\
\hline 29 & 23.94 & 1-tetradecene & 0.47 & - \\
\hline 30 & 24.14 & tetradecane & 1.16 & 0.95 \\
\hline 31 & 24.55 & junipene & 0.30 & - \\
\hline 32 & 24.99 & $\alpha$-ionone & - & 0.61 \\
\hline 33 & 26.47 & $\beta$-ionone & 0.20 & 1.32 \\
\hline 34 & 26.92 & farnesene & 0.89 & - \\
\hline 35 & 29.04 & hexadecane & 0.38 & - \\
\hline 36 & 31.31 & heptadecane & 0.13 & - \\
\hline
\end{tabular}




\section{Comparison of volatile components in banana flowers and bracts}

The identified compounds in banana flowers and bracts indicated that banana flowers have more volatile components, and 11 comment materials in the two samples, the nonanal is the highest ingredient in the two materials. In food industry, nonanal is a food additive, and it is used as an intermediate in organic synthesis, spices raw materials, and rubber accelerator [9]. In addition, nonanal is a natural spice with rose fragrance, it widely exists in Germany essential oil (like rose and neroli oil) [10]. Hexanal has apple aroma, it is usually used as spices synthetic intermediates, raw food industries and pharmaceutical industries [11]. The content of nonanal and hexanal in banana flowers and bracts was higher than other components, so the two aldehydes may be the material basis of aromas of banana flowers and bracts.

\section{Conclusion}

Headspace solid-phase microextraction method is a solvent-free, rapid method to analyze the volatile components. It allows volatile components to be extracted in its natural state. The volatile components of banana flowers and bracts were isolated and identified by headspace solid-phase microextraction and gas chromatography-mass spectrometry. 31 components were identified in banana flowers, but only 16 components were identified in banana bracts. The contents of aldehydes were the highest in the two samples, and the content of aldehydes in the banana flowers was higher than bract samples, so it might lead to the richer fragrance in banana flowers than in the bracts. A variety of aldehydes are used in the food and fragrance industry, so the aldehydes may be responsible for the aromas of banana flowers and bracts. In addition, the content of nonanal and hexanal is higher in the two materials, so the banana flowers and bracts can be used as a natural source to extraction of nonanal and hexanal. The study could provide a scientific basis for the further development of banana flowers and bracts.

\section{Acknowledgements}

This work was supported by the project "the special funds of outstanding young scientists training object in Guizhou (2013, NO.46)". The authors thank the government of China for their financial support.

\section{References}

1. P. Yang, Y.Y. Chen, G.H. Li, S.X. Zhong. Our banana industry: Status, problems and prospects. J. Fruit Sci, 5, (2010)

2. K.S. Wickramarachchi, S.L. Ranamukhaarachchi. Preservation of fiber-rich banana blossom as a dehydrated vegetable. Science Asia, (2005)

3. J.J. Bhaskar, S, M. Chilkunda, N.D. P.V. Salimath. Banana (Musa sp. var. elakki bale) flower and pseudostem: dietary fiber and associated antioxidant capacity.J. Agric. Food Chem, 1, (2012)

4. J. Ganugapati, A. Baldwa, S. Lalani. Molecular docking studies of banana flower flavonoids as insulin receptor tyrosine kinase activators as a cure for diabetes mellitus, Bioinformation. African Journal of Biotechnology, 5, (2012)

5. Z.W. Sheng, W.H. Ma, J.H. Gao, J.Y. Li, L.N. Han, Z.Q. Jin. Brazilian banana bud nutrients in different parts of the analysis and evaluation. Food Sci (in Chinese), 31, (2010)

6. Z.W. Sheng, W.H. Ma, J.H. Gao, Y. BI, W.M. Zhang, H.T. Dou, Z.Q. Jin. Antioxidant properties of banana flower of two cultivars in China using 2,2-diphenyl-1-picrylhydrazyl (DPPH,) reducing power, 
2,2'-azinobis-(3-ethlbenzthiazoline-6-sulphonate (ABTS) and inhibition of lipid peroxidation assays. African Journal of Biotechnology, 21, (2011)

7. Z.W. Sheng, W.H. Ma, Z.Q. Jao, Y. Bi, Z.G. Sun, H.T. Don, J.H. Gao, J.Y. Li, H.T. Han. Investigation of dietary fiber, protein, vitamin $\mathrm{E}$ and other nutritional compounds of banana flower of two cultivars grown in China. African Journal of Biotechnolog, 25, (2010)

8. Z.W. Sheng, Y.P. Tang, Y.J. Chen, W.M. Zhang, W.H. Ma, Z.Q. Jin. Antioxidant activity of different parts of Brazil banana bud extract. Food Sci (in Chinese), 17, (2010)

9. Y.M. Gao, X.L. Wang, Y. Gong, H. Wang, Q. Liao. Headspace gas chromatography-mass spectrometry for coated fabric of fragrances nonanal. Analytical Instruments, 6, (2011)

10. M.M. Liu, X.Y. Xi. Prepared mustard oxidative cleavage of methyl nonanal inquiry. Chemical Industry Times, 4, (2012)

11. L. Wang, T.X. Cheng, G.D. Zhou, Y.L Bi, K. J. Zhen. Study hexanol (oxidative) dehydrogenation of n-hexana. Journal of Molecular Catalysis (china), 6, (2003)

12. P.Y. Tian, X.Z. Gu, J.M. Wang, Y.Y. Li, W.Y. Kang. HS-SPME-GC-MS analysis of hair and blue wooden aboveground and root volatile components. China J Exp Tradit Med Form, 6, (2011) 